\title{
Review
}

\section{International Society of Urological Pathology (ISUP) Consensus Conference on Handling and Staging of Radical Prostatectomy Specimens. Working group 1: specimen handling}

Hemamali Samaratunga ${ }^{1}$, Rodolfo Montironi ${ }^{2}$, Lawrence True ${ }^{3}$, Jonathan I Epstein ${ }^{4}$, David F Griffiths ${ }^{5}$, Peter A Humphrey ${ }^{6}$, Theo van der Kwast ${ }^{7}$, Thomas M Wheeler ${ }^{8}$, John R Srigley ${ }^{9}$, Brett Delahunt ${ }^{10}$, Lars Egevad ${ }^{11}$ and The ISUP Prostate Cancer Group*

${ }^{1}$ Department of Pathology, Aquesta Pathology, Brisbane, QLD, Australia; ${ }^{2}$ IFCAP, Section of Pathological Anatomy, Polytechnic University of the Marche Region, School of Medicine, United Hospitals, Ancona, Italy; ${ }^{3}$ Department of Pathology, University of Washington Medical Center, Seattle, WA, USA; ${ }^{4}$ Department of Pathology, Johns Hopkins Hospital, Baltimore, MD, USA; ${ }^{5}$ Department of Pathology, Cardiff University School of Medicine, University Hospital of Wales, Cardiff, UK; ${ }^{6}$ Department of Pathology and Immunology, Washington University School of Medicine, St Louis, MO, USA; ${ }^{7}$ Department of Pathology, University Health Network and University of Toronto, Toronto, ON, Canada; ${ }^{8}$ Department of Pathology, Baylor College of Medicine, Houston, TX, USA; ${ }^{9}$ Department of Pathology and Molecular Medicine, McMaster University, Hamilton, ON, Canada; ${ }^{10}$ Department of Pathology and Molecular Medicine, Wellington School of Medicine and Health Sciences, University of Otago, Wellington, New Zealand and ${ }^{11}$ Department of OncologyPathology, Karolinska Institutet, Stockholm, Sweden

The 2009 International Society of Urological Pathology Consensus Conference in Boston made recommendations regarding the standardization of pathology reporting of radical prostatectomy specimens. Issues relating to the handling and processing of radical prostatectomy specimens were coordinated by working group 1 . Most uropathologists followed similar procedures for fixation of radical prostatectomy specimens, with $51 \%$ of respondents transporting tissue in formalin. There was also consensus that the prostate weight without the seminal vesicles should be recorded. There was consensus that the surface of the prostate should be painted. It was agreed that both the prostate apex and base should be examined by the cone method with sagittal sectioning of the tissue sample. There was consensus that the gland should be fully fixed before sectioning. Both partial and complete embedding of prostates was considered to be acceptable as long as the method of partial embedding is stated. No consensus was determined regarding the necessity of weighing and measuring the length of the seminal vesicles, the preparation of whole mounts rather than standardized blocks and the methodology for sampling of fresh tissue for research purposes, and it was agreed that these should be left to the discretion of the working pathologist.

Modern Pathology (2011) 24, 6-15; doi:10.1038/modpathol.2010.178; published online 10 September 2010

Keywords: processing; prostate adenocarcinoma; prostatic apex; prostatic base; sampling; seminal vesicle

Correspondence: Dr H Samaratunga, FRCPA, Department of Pathology, Aquesta Pathology, 51 Douglas Street, Milton, QLD 4064, Australia.

E-mail: hema@aquesta.com.au

*See Appendix.

Received 16 December 2009; revised 4 August 2010; accepted 12 August 2010; published online 10 September 2010
Handling radical prostatectomy specimens in a manner that is attentive to parameters that help guide clinical management is critical for ensuring accurate histopathological assessment and staging. ${ }^{1-5}$ Prognosis after radical prostatectomy relies, in part, on accurate characterization of a number of histological features, including the status of the surgical 
margin, extraprostatic extension, Gleason grade, tumor volume and whether tumor extends into the seminal vesicles and/or is metastatic to regional lymph nodes. Information gained from radical prostatectomy specimens is used in prognostic instruments such as the Kattan nomograms and Partin tables to predict outcome, measured as the probability of biochemical recurrence and long-term survival. ${ }^{6,7}$ This information is also used for selecting and instituting adjuvant therapy such as radiotherapy or hormone therapy. ${ }^{8,9}$ The marked increase in the number of radical prostatectomies in recent years $^{10}$ has increased the workload on surgical pathology laboratories. Nevertheless, it is important that these specimens are handled appropriately so as not to compromise the accuracy of the pathologic data. Incorrect practices might result in irretrievable loss of histological information.

Several recent publications have outlined protocols for the systematic handling of radical prostatectomy specimens, with recommendations regarding what the authors perceive to be the most appropriate practice; ${ }^{3-5,11}$ yet, it is clear that many different methods are employed in the handling, sampling and processing of these specimens. A recent web-based survey was used to identify current practice in the European uropathology community. Although many practices were commonly employed by most pathologists, some vary and it is clear that there is a need for standardization. $^{11}$

\section{International Society of Urological Pathology Survey and Consensus Conference}

In order to identify the methods most commonly employed by urological pathologists worldwide, a web-based survey on handling and reporting of radical prostatectomy specimens was distributed to 255 members of the International Society of Urological Pathology.

The International Society of Urological Pathology survey was followed up with a consensus conference held in conjunction with the 2009 Annual Scientific Meeting of the United States and Canadian Academy of Pathology held in Boston, Massachusetts. The aim was to obtain consensus relating to the handling and reporting of radical prostatectomy specimens. Those who completed the electronic survey were invited to attend the consensus conference, which was held on 8 March. The detailed process related to the survey and consensus meeting are reported in an introductory paper. ${ }^{12}$

Representatives from five working groups appointed to coordinate the consensus process presented background information and results from detailed literature reviews to the meeting. The survey results were then discussed with the objective of achieving agreement on controversial issues.
Following this, a ballot was taken on a series of questions that were designed to address these controversial issues and an achievement of $65 \%$ agreement on voting was considered to be consensus. With a few exceptions, there was agreement between the survey results and the consensus conference results. The results of the individual working group reports related to T2 substaging, extraprostatic extension, seminal vesicle and lymph node involvement and margin status are reported separately. ${ }^{13-16}$

Many recommendations of this consensus conference have already been incorporated into international guidelines, including the recent College of American Pathologists protocol and checklist for reporting adenocarcinoma of the prostate and the structured reporting protocol for prostatic carcinoma from the Royal College of Pathologists of Australasia. ${ }^{17,18}$

\section{Specimen transportation}

Typically, radical prostatectomy specimens are transported in 10\% buffered formal saline. Specimen jars containing fixative are usually stored in operating theaters and the surgical specimen is immersed in fixative following removal and then transported to the laboratory. On occasions, fresh tissue is harvested in the laboratory and the time interval that a prostatectomy specimen can be kept fresh without compromising cellular morphology is unclear. Long pre-fixation intervals invariably occur with robotic-assisted laparoscopic prostatectomy and this can be up to $2 \mathrm{~h} .{ }^{19}$ Despite this, it has been shown that up to $2 \mathrm{~h}$ of warm ischemia (time without fixation) does not alter protein, DNA or RNA conformation and that there is satisfactory preservation of microscopic and immunohistochemical features. ${ }^{19}$ Somewhat in contradiction of this, it has also been reported that there are increasing alterations of gene expression with longer intervals of warm ischemia and significant changes have been shown even after $1 \mathrm{~h} .{ }^{20}$ It is clear from these data that further studies are necessary in order to assess the duration of warm ischemia that is acceptable without compromising histological interpretation of radical prostatectomy specimens.

Of the participants of the survey, a majority reported that they received specimens transported in formalin, whereas no respondent reported the use of other fixatives. A majority of the respondents also reported that at least on occasions they received specimens that had been transported without fixative (Table 1). As the intraoperative warm ischemia interval is often unknown, the conference felt it prudent to note that transportation of unfixed specimens should be discouraged. In those cases where this is unavoidable, it was pointed out that the specimen should be placed in fixative as soon as possible after arrival at the pathology laboratory and 
Table 1 Comparison of survey results with consensus conference results

\begin{tabular}{|c|c|c|c|c|c|}
\hline \multicolumn{3}{|l|}{ Survey results } & \multicolumn{3}{|c|}{ Consensus conference results } \\
\hline & $\begin{array}{l}\text { Survey: number } \\
\text { responding }\end{array}$ & Survey \% & $\begin{array}{l}\text { CC: number } \\
\text { responding }\end{array}$ & $C C \%$ & \\
\hline Specimen transportation fresh at least in some cases & 154 & $62 \%$ & NA & & \\
\hline Prostate weight without SV & 156 & $24 \%$ & 111 & $67 \%$ & Consensus \\
\hline All three dimensions of prostate & 149 & $92 \%$ & 111 & $95 \%$ & Consensus \\
\hline $\begin{array}{l}\text { Should prostate surface be painted or dipped in } \\
\text { silver nitrate? }\end{array}$ & 154 & $98 \%$ & NA & & \\
\hline Should number of colors be standardized? & NA & NA & 110 & Yes $55 \%$ & \\
\hline$\geq 2$ colors? & 153 & $81 \%$ & 90 & $79 \%$ & Consensus \\
\hline Fresh tissue for research & 156 & $64 \%$ & NA & NA & \\
\hline Fresh sample from cut surface & 100 & $68 \%$ & NA & NA & \\
\hline Prostate fully fixed before cutting & 157 & $80 \%$ & 108 & $77 \%$ & Consensus \\
\hline Cutting the apex 'cone method' & 157 & $91 \%$ & 110 & $100 \%$ & Consensus \\
\hline Sagittal slicing of apex & 91 & $58 \%$ & 110 & $79 \%$ & Consensus \\
\hline Cutting the base 'cone method' & 157 & $71 \%$ & 110 & $77 \%$ & Consensus \\
\hline Sagittal slicing of base & 79 & $50 \%$ & 88 & $84 \%$ & Consensus \\
\hline Complete embedding of prostate & 157 & $59 \%$ & 109 & $62 \%$ & \\
\hline Partial embedding & 157 & $24 \%$ & 109 & $63 \%$ & \\
\hline If partial embedding, method should be documented & NA & NA & 95 & $94 \%$ & Consensus \\
\hline Use of whole mounts & 148 & $16 \%$ & NA & NA & \\
\hline Biopsy cancer but no cancer in RP? pT0 & NA & NA & 106 & Yes $74 \%$ & Consensus \\
\hline
\end{tabular}

NA, not asked, so does not apply; SV, seminal vesicle; CC, consensus conference; RP, radical prostatectomy specimen.

that an estimate of the warm ischemia interval should be recorded.

\section{Specimen weight and dimensions}

It is recognized that the prostate gland and seminal vesicles are different organs, and can vary markedly in size and weight. In view of this, it was agreed that the true weight of the prostate gland can only be determined if the seminal vesicles are detached from the prostate gland before weighing (Table 1). The weight of the prostate gland is often correlated with the radiologically estimated weight, ${ }^{21,22}$ and although the practical significance of this in patient management may be limited, it was agreed that this should recorded, as these data were of potential interest for research purposes. The survey found that $76 \%$ of respondents weighed the prostate with the seminal vesicles attached; yet, at the meeting, there was consensus that the prostate weight without the seminal vesicles should be recorded. It was considered that this is a relatively simple procedure that should not be onerous even in a busy surgical pathology laboratory. It was noted that some urologists request the weight of the entire specimen to justify assigning a level of difficulty to the surgical procedure, in which case the weights of the prostate and the seminal vesicles could be combined. There was consensus that all three dimensions of the prostate, that is, apical to basal (vertical), left to right (transverse) and anterior to posterior (sagittal), should be recorded. On this point, 92 and $95 \%$ agreement was achieved in the survey and consensus conference, respectively. It was also agreed that given the tapering shapes of the prostates, the maximum length of each dimension should be taken.

\section{Painting the surface}

Accurate assessment of surgical margin is essential for the evaluation of radical prostatectomy specimens. ${ }^{23}$ Although the true surgical margin can appear distinct, this may be difficult to differentiate from artefactual margins that result from specimen cutting and embedding. Painting the surface or dipping in silver nitrate is necessary for assessment of the surgical margins. ${ }^{2,24}$ This is especially important as problems may occur when slicing the prostate. In particular, it is easy to inadvertently flip slices once they are cut, thus obscuring the laterality of the specimen. The anterior and posterior prostates may be identified microscopically through examination of the mid portion of the prostate (the posterior aspect is predominantly flat and contains intraprostatic portions of seminal muscles and ejaculatory ducts) and ideally two colors should be used to indicate the right and left sides. Another method that may be employed when one color (or India ink) is used to mark the surgical margin of the prostate is to make a cut in a specific location such as the anterolateral aspect of the gland (Figure 1a). More than two colors may be used and this is dependent on the preference of the pathologist. Of survey respondents, 98\% reported that they painted or dipped the surface in silver nitrate and $81 \%$ reported using two or more colors. 


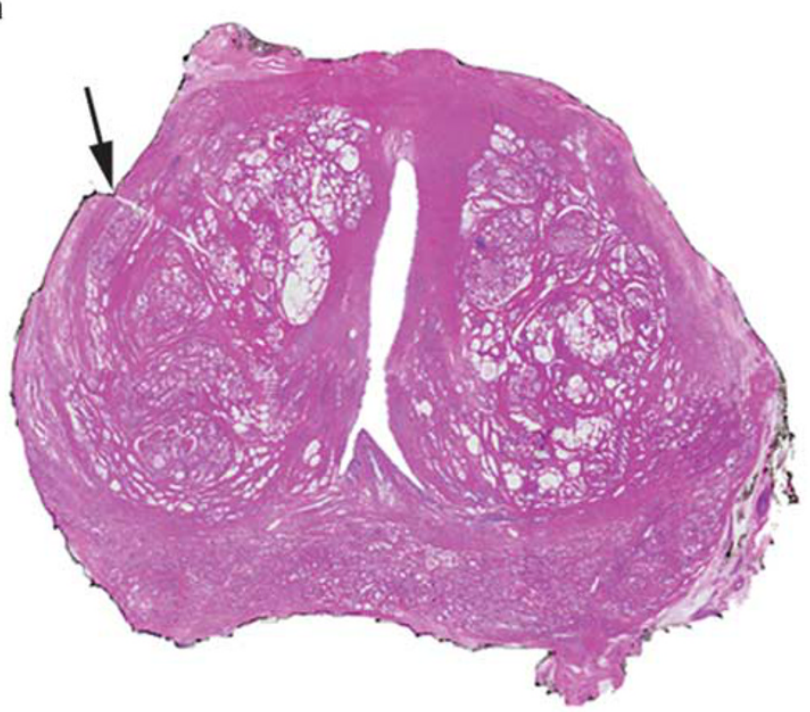

b

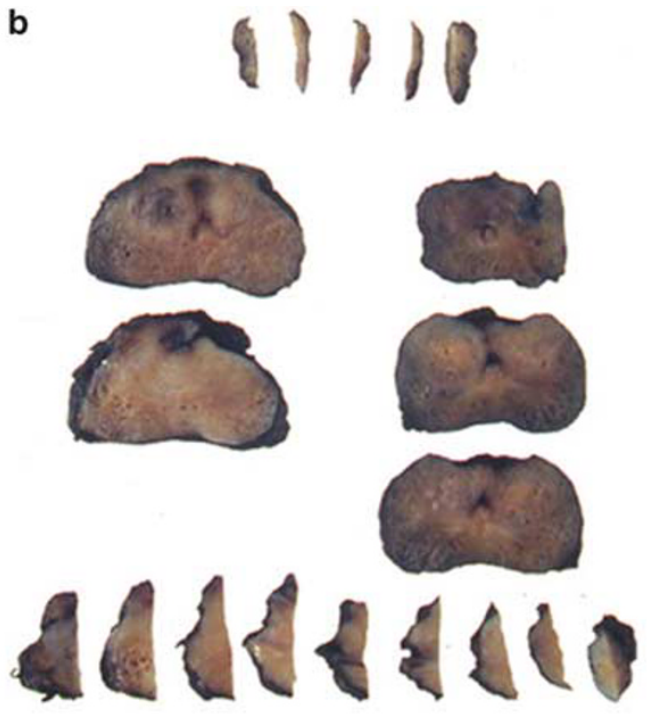

c

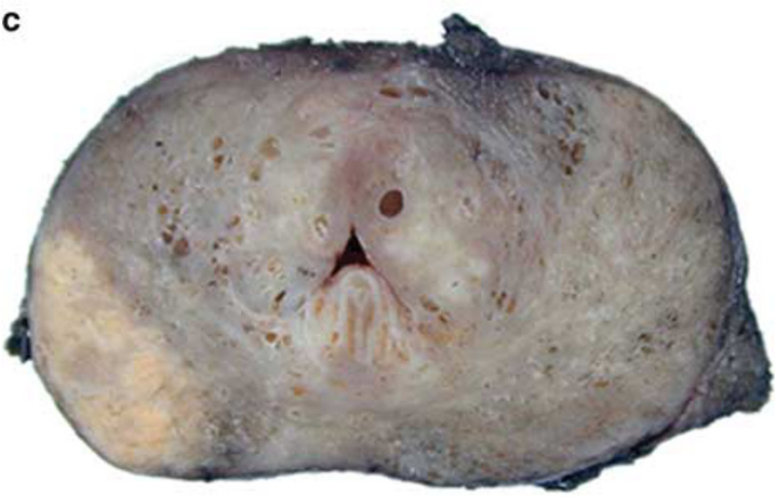

d

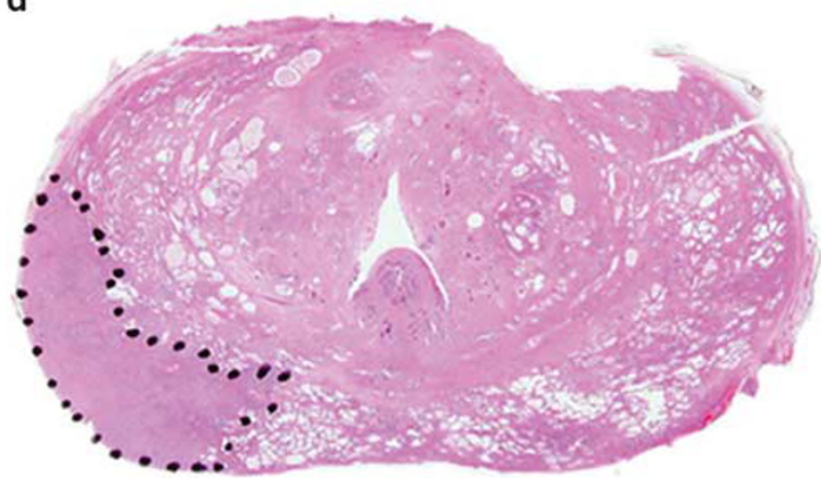

Figure 1 (a) Whole-mount section of prostate with a cut at the left anterolateral aspect of the gland (arrow) to allow orientation of the specimen. (b) Completely blocked prostate with sagittal sectioning of the coned apex and base. (c, d) Grossly visible carcinoma and corresponding hematoxylin and eosin-stained section.

Although a majority of the participants at the meeting considered that the number of colors used in marking the prostate should be standardized, there was no consensus as to what these should be. Ninety participants responded to the question as to the number of colors that should be employed, with $79 \%$ of this group suggesting the use of at least two colors. Although there was consensus that at least two colors should be used, there was no consensus on standardizing the actual number of colors that should be employed.

\section{Harvesting fresh tissue for research}

Although initially harvested only for discovery research, tissue samples are increasingly being obtained as integral components of clinical trials. ${ }^{25}$ In the future, fresh samples may be a required component of clinical management to assay analytes that cannot be accurately evaluated using formalinfixed, paraffin-embedded tissue. The survey yielded a range of diverse techniques for obtaining fresh samples. Although all research uropathologists have the goal of preserving unfixed cells or tissue as rapidly as possible, they differ in methodology, the amount of tissue that is collected for research, the yield of cells of interest, the time and effort involved in obtaining research samples and in annotation data. Of note, the tissue for research that is rapidly frozen, by immediate immersion in isopentane that is pre-cooled to a near-slush state in liquid nitrogen, yields sections of both prostate blocks and of needle biopsies that are of sufficient quality for cells to be microscopically identified and removed by laser microdissection, and their RNA expression profiles determined..$^{25,26}$

Although macromolecules (DNA, RNA, and protein) can be retrieved from formalin-fixed tissue for molecular characterization, fresh or fresh-frozen tissue samples are preferred, as formalin adversely affects the quality of nucleic acids (by fragmentation) and of proteins (by crosslinking). ${ }^{27}$ Formalin fixation may not have as severe an effect on RNA quality for genome-wide expression analysis as does long-term storage. ${ }^{28}$ In the survey, we found that a 
variety of methods for obtaining fresh tissue are practiced. ${ }^{29,30}$ Regardless of the method chosen to obtain fresh tissue, there are several principles that most practitioners follow. (1) Tissue sampling is undertaken in a manner that does not compromise histopathological data necessary for clinical management. These data include grading and staging, estimation of volume and characterization of the relationship of tumor to the surgical margin. (2) Harvesting of research tissue should produce high yields of high-quality tissue from a substantial proportion of cases. ${ }^{11}$

A majority of survey respondents indicated that, in their institution, fresh tissue was harvested by the pathologist or urologist in at least some cases (Table 1). This is a much higher rate than that previously reported in a survey of European pathologists, where the rate was $29 \%$, although this was $55 \%$ for European academic pathologists. ${ }^{11}$ The higher rate in the International Society of Urological Pathology survey may be explained, at least in part, by a greater proportion of university (academic) practitioners in the survey sample. A variety of sampling methods were reported. Most respondents sampled the cut surface using a shave technique, punch biopsies or, rarely, fine needle aspirates or scrapings. A further $20 \%$ took core biopsies using an external approach and it was noted that this did not compromise pathological assessment, ${ }^{30}$ although it was recognized that this may be a possibility if the biopsy cores are excessively thick.

\section{Fixing and slicing the prostate}

Fixatives preserve the physical and chemical properties of tissues and prevent autolysis. Fixation may be broadly categorized as the effects of dehydrants, heating, crosslinking agents, acids and any combination of these. ${ }^{31}$ Formaldehyde as a $10 \%$ neutral buffered formalin solution is the most widely used fixative and the speed of fixation depends on the rate of diffusion and the rate of chemical reaction between the fixative and the various tissue components. It is recommended that specimens be fully immersed in at least 20 times their own volume of buffered formal saline with at least $1 \mathrm{~h}$ of fixation time per $\mathrm{mm}$ of tissue thickness being required. ${ }^{32}$ Routinely, tissues are fixed for about $24 \mathrm{~h}$; however, the ideal length of fixation time for prostatic tissue remains undetermined.

Slicing and cutting of blocks is facilitated when the prostate is fixed because of the firmness that fixation imparts. It is difficult to obtain uniformly thin slices if the prostate is sliced fresh, particularly if it is a very large gland with nodularity imparted by benign hyperplasia. Additionally, reliability of immunohistochemical staining may be compromised with short fixation times. It has been shown that loss of expression of p27 was more marked with same-day cutting when compared with fixation for
$>1$ day. ${ }^{33}$ Interestingly, expression was improved following injection of formalin into the prostate. Fixation of a solid organ such as the prostate can be a slow process and autolytic damage may occur if the fixative does not reach the central part of the specimen. Excessive duration of formalin fixation can also be detrimental and often results in antigen masking, ${ }^{34}$ and optimum high-molecular-weight cytokeratin immunoreactivity has been demonstrated after $6 \mathrm{~h}$ of formalin fixation. ${ }^{35}$ Although longer fixation times appear not to have an effect on light microscopic features, there appears to be an adverse effect on the quality of tissue DNA. ${ }^{36}$

Techniques for enhancing fixation, such as formalin injection and microwaving, have been shown to produce satisfactory fixation at a light microscopic level and improve immunohistochemical expression when compared with conventional fixation. These methods also have no influence on morphology or tumor volume estimation. ${ }^{37,38}$

For fixation by formalin injection, $20 \mathrm{ml} 10 \%$ buffered formal saline is introduced into the prostate at multiple sites using a 23-G needle. To ensure homogenous fixation, it is recommended that the needle be inserted deeply and the solution injected while the needle is retracted slowly. ${ }^{38}$

Microwaving of tissues for 1 to $2 \mathrm{~min}$ at $60{ }^{\circ} \mathrm{C}$ has been shown to enhance fixation and preserve nucleic acids. ${ }^{39}$ In the case of radical prostatectomy specimens, microwave fixation can be undertaken before cutting, ${ }^{37}$ although cut specimens may also be microwaved with satisfactory results.

Although full fixation is considered to be achieved after immersion for many hours (usually overnight) in formalin, it was agreed at the meeting that this can also be attained with a few hours in formalin when combined with enhanced fixation techniques. There was consensus that for routine assessment the prostate should be fully fixed before the cutting of tissue blocks for embedding.

\section{Blocking the Apex}

Histological examination of the prostatic apex is essential for assessment of extraprostatic extension and resection margin tumor positivity. The resection margin in this area includes the entire inferior margin of the prostate, and is considered positive if cancer reaches the inked surface. Carcinoma close to, but not involving the margin, is not considered to represent a positive surgical margin, as this has not been shown to have prognostic significance, ${ }^{40,41}$ whereas a true positive margin in this location does predict outcome. ${ }^{42}$ The shave method, with en face blocking of the apex, will not permit assessment of the entire inferior inked margin. In such instances, the margin is considered positive if the apical block contains cancer and this will result in a high falsepositive rate. Assessment of extraprostatic extension is also more difficult using this technique when 
compared with the cone method, and this compounds the already difficult assessment of the prostatic apex. Before sectioning of the cone, the apex should ideally be separated from the last parallel slice of the body taken perpendicular to the rectal surface.

There was consensus that the cone method should be used for blocking the apex with 100\% agreement at the conference. On this point in the survey, $91 \%$ agreement had been reached. There was also consensus that sagittal slicing should be used for the sectioning of the coned apex (Figure 1b). As discussed at the conference, sagittal slicing offers the advantage over radial slicing by producing tissue blocks of uniform thickness.

\section{Blocking the Base}

Bladder neck margin positivity is an important prognostic indicator, ${ }^{43}$ and trimming of the shave block can result in loss of the inked margin. As in the case of the prostatic apex, the margin is considered positive if cancer is present at the inked surface, but not if tumor lies close to a margin. It may also not be possible to ascertain true bladder neck involvement by tumor. Ideally, the base should be separated from the first parallel slice of the body, taken perpendicular to the posterior surface.

The consensus was that the cone method should be used for cutting the base and that sagittal slicing of the basal cone should be performed (Figure 1b). Similar to the situation regarding the prostatic apex, it was noted that sagittal slicing offers the advantage over radial slicing by producing tissue blocks of uniform thickness. However, it was recognized that the taking of a thin shave margin at the base is not as undesirable when compared with shaving of the apical margin. The bladder neck margin typically consists of thick muscle bundles outside of the prostate, and if a thin shave margin shows any carcinoma, this generally indicates extraprostatic extension in addition to surgical margin positivity.

\section{Partial or Total Embedding of the Radical Prostatectomy Specimen}

Compounded by cost restraints is the question as to how much of a radical prostatectomy specimen should be blocked and whether complete embedding is essential. Processing a completely embedded radical prostatectomy specimen, particularly if the prostate is large, can be both costly to the laboratory and time consuming for the technical staff. This has to be weighed against the difficulties in identifying prostate cancer at gross examination of the specimen and the risk of overlooking prognostically important information. A variety of partial embedding methods are available, with the ideal method depending on whether the tumor is cT1c or cT2 disease, ${ }^{1}$ and whether the cancer is grossly visible. The most efficient method of sectioning should provide maximum information in terms of Gleason score, detection of extraprostatic extension and surgical margin positivity and seminal vesicle involvement through examination of the fewest number of sections.

It has been shown that submission of grossly visible stage T2 (palpable) cancer along with standard sections of the proximal and distal margins, the base of seminal vesicles and the most apical section, $96 \%$ of positive surgical margins and $91 \%$ of instances of extraprostatic extension are detected, when compared with complete embedding. ${ }^{44}$ Using this method, a mean number of 13 blocks was taken, which compared with 42 blocks following complete sectioning. The submission of alternate whole-mount sections was found to be associated with a lower detection rate. Using the same method, all of the cases with extraprostatic extension and surgical margin positivity were detected in cT1 (nonpalpable) cases with grossly visible lesions. ${ }^{44}$ In another study using partial embedding of alternate slices, the Gleason score was incorrect in $4 \%$ of cases, whereas there was a $15 \%$ false-negative rate for extraprostatic extension. ${ }^{45}$ In a study by Sehdev et al, ${ }^{46}$ cT1c tumors with one or more adverse pathological findings, such as Gleason score $\geq 7$, positive margins and extraprostatic extension, were compared using ten different sampling techniques. The optimal method consisted of embedding every posterior section and one mid anterior section from the right and left sides of the gland. If either of the anterior sections had sizable tumor, all anterior slices were blocked in a second step. This method detected $98 \%$ of tumors with Gleason score $\geq 7,100 \%$ of positive margins and $96 \%$ of cases with extraprostatic extension, through examination of a mean number of 27 slides. It was also shown that sampling of sections ipsilateral to a previously positive needle biopsy detected $92 \%$ of Gleason score $\geq 7$ cancers, $93 \%$ of positive margins and $85 \%$ instances of extraprostatic extension, from a mean number of 17 slides.

In response to the question relating to how much of the prostate should be blocked, $>60 \%$ of conference participants supported complete embedding, whereas $>60 \%$ also supported partial embedding. This apparent contradiction arose as several respondents selected both options depending on the situation. In view of this, it was concluded that both methods were considered acceptable. Pathologists have to balance the extra expense and time involved in processing entire specimens against the risk of missing important prognostic parameters, and decide whether partial or complete embedding should be performed. There was consensus that if partial embedding is performed, a specific protocol should be followed and the methodology should be documented in the pathology report. 


\section{Use of Whole Mounts}

The use of whole mounts of sections from radical prostatectomy specimens has the advantage of displaying the architecture of the prostate and the location of tumor nodules more clearly (Figure 1c and d); furthermore, it is easier to compare the pathological findings with those obtained from digital rectal examination and transrectal ultrasound. The whole-mount technique has been adopted routinely in some laboratories and its use is recommended in the European clinical setting. ${ }^{47}$ Despite this, whole mounts are more difficult to prepare and the cutting of large blocks of uniform thickness requires considerable experience, although this may be assisted through the use of prostate cutting device, for which purpose an ordinary delicatessen meat slicer would suffice. Additionally, the paraffin blocks and glass slides require dedicated containers because of their large size. Of relevance, whole mounts appear not to be superior to sections from standard blocks in detecting adverse pathological features. ${ }^{48}$

From the survey, a majority of respondents reported using standard blocks and only $16 \%$ reported the use of whole mounts, for at least some slices (Table 1). A minority reported using both methods. On discussion at the consensus conference it was considered that both standard blocks and whole mounts were acceptable for examination of radical prostatectomy specimens, although no ballot was taken on this point.

\section{Radical prostatectomy specimens with no carcinoma on initial evaluation}

In $0.07-4.2 \%$ of cases and also occasionally after neoadjuvant endocrine therapy, cancer may not be detected following sectioning of a radical prostatectomy specimen. ${ }^{49-51}$ The incidence of this so-called vanishing cancer phenomenon appears to have increased in recent years, rising in one institution from $0.07 \%$ in 1997 to $0.13 \%$ in 2004 and to $0.34 \%$ in $2005 .{ }^{52-54}$ Additionally, Zynger et $a l^{55}$ also reported an increase from $0 \%$ of cases in 2002 to $4.2 \%$ in 2006, whereas Trpkov et al ${ }^{56}$ found an incidence of $0.67 \%$ after 10 -core positive biopsy to be higher than that previously reported.

The procedure to follow in such instances is well described and this will result in detection of cancer in a high percentage of cases. ${ }^{49-51}$ As an initial step, the needle biopsy should be reviewed to confirm a diagnosis of malignancy. The radical prostatectomy sections should also be reviewed in order to confirm the absence of cancer. In those cases where initial sampling was by partial embedding, all residual tissues should be blocked. Atypical foci should be immunostained for racemase (AMACR) and basal cell markers and, where appropriate, cytokeratin and PSA. Deeper sections of blocks from the same sextant region of the positive needle biopsy and from areas showing high-grade PIN should then be examined. If no cancer is found, the paraffin blocks should then be turned and multiple sections from the other side of the block should be prepared. Reviewing the description of the macroscopic appearance of the external surface and cut surfaces of the surgical specimen, as well as inspecting the contour of the tissue sections on the slides, may confirm that part of the tissue has been cut away, either during surgery or during processing.

If cancer is not found after all these steps, and cancer in the initial biopsy is confirmed, the possibility of a specimen mix-up needs to be considered and DNA analysis for identification of the origin of the tissue should be considered.

If the biopsy is proven to have cancer and there is no cancer in the radical prostatectomy specimen, there is debate as to whether this should be considered to be pT2 through combining the biopsy and prostatectomy findings, or pT0-effectively disregarding the biopsy result and considering only the findings of the radical prostatectomy specimen. pT2 tumors are of clinical significance, with a 5-year risk of PSA failure of $13 \%$ for pT2a and of $23 \%$ for pT2c. In contrast, patients with a biopsy positive for cancer, but with no cancer in the radical prostatectomy specimen, have no increased risk of tumor recurrence or progression. ${ }^{50,56-59}$

European urologists have suggested that in these cases, pT2 could be further characterized as pT2(-), where (-) indicates that cancer was not detected in the surgical specimen. Another alternative is to grade these tumors as pT2 $(+\mathrm{bx} /-\mathrm{rp})$ to indicate the special situation of a positive biopsy $(+b x)$ with no cancer detected in the radical prostatectomy specimen $(-\mathrm{rp}){ }^{60}{ }^{60}$ These observations differed from the responses obtained at the consensus conference, where the opinion was that the radical prostatectomy findings should stand alone when pT staging is considered (Table 1). There was consensus that if no cancer was found in the radical prostatectomy specimen after detailed examination, then the tumor should be classified as pT0.

\section{Disclosure/conflict of interest}

The authors declare no conflict of interest.

\section{References}

1 Srigley JR. Key issues in handling and reporting radical prostatectomy specimens. Arch Pathol Lab Med 2006; 130:303-317.

2 Bostwick DG, Montironi R. Evaluating radical prostatectomy specimens: therapeutic and prognostic importance. Virchows Arch 1997;430:1-16.

3 Epstein JI, Amin M, Boccon-Gibod L, et al. Prognostic factors and reporting of prostate carcinoma in radical prostatectomy and pelvic lymphadenectomy specimens. Scand J Urol Nephrol 2005;39(Suppl):34-63. 
4 Montironi R, Mazzucchelli R, van der Kwast $\mathrm{T}$. Morphological assessment of radical prostatectomy specimens. A protocol with clinical relevance. Virchows Arch 2003;442:211-217.

5 Sakr WA, Grignon DJ. Prostate. Practice parameters, pathologic staging and handling radical prostatectomy specimens. Urol Clin North Am 1999;26:453-463.

6 Stephenson AJ, Scardino PT, Eastham JA, et al. Postoperative nomogram predicting the 10 -year probability of prostate cancer recurrence after radical prostatectomy. J Clin Oncol 2005;23:7005-7012.

7 Kattan MW, Wheeler TM, Scardino PT. Postoperative nomogram for disease recurrence after radical prostatectomy for prostate cancer. Am J Clin Oncol 1999;17:1499-1507.

8 Barry MJ, Albertsen PC, Bagshaw MA, et al. Outcomes for men with clinically nonmetastatic prostate carcinoma managed with radical prostatectomy, external beam radiotherapy or expectant management: a retrospective analysis. Cancer 2001;91:2302-2314.

9 Vaishampayan U, Hussain M. Adjuvant chemo-/hormonal therapy trials for locally advanced prostate cancer. Curr Oncol Rep 2000;2:402-408.

10 Hussain S, Gunnell D, Donovan J, et al. Secular trends in prostate cancer mortality, incidence and treatment: England and Wales. BJU Int 2008;101:547-555.

11 Egevad L, Algaba F, Berney DM, et al. European Network of Uropathology. Handling and reporting of radical prostatectomy specimens in Europe: a webbased survey by the European Network of Uropathology. Histopathology 2008;53:333-339.

12 Egevad L, Srigley JR, Delahunt B. International Society of Urological Pathology (ISUP) consensus conference on handling and staging of radical prostatectomy specimens: rationale and organization. Mod Pathol 2011;24:1-5 (this issue).

13 van der Kwast T, Amin MB, Billis A, et al. International Society of Urological Pathology (ISUP) consensus conference on handling and staging of radical prostatectomy specimens. Working group 2: T2 substaging and prostate cancer volume. Mod Pathol 2011;24:16-25 (this issue).

14 Magi-Galluzzi C, Evans A, Delahunt B, et al. International Society of Urological Pathology (ISUP) consensus conference on handling and staging of radical prostatectomy specimens. Working group 3: extraprostatic extension, lymphovascular invasion and locally advanced disease. Mod Pathol 2011;24:26-38 (this issue).

15 Berney D, Wheeler T, Grignon D, et al. International Society of Urological Pathology (ISUP) consensus conference on handling and staging of radical prostatectomy specimens. Working group 4: seminal vesicles and lymph nodes. Mod Pathol 2011;24:39-47 (this issue).

16 Tan PH, Cheng L, Srigley JR, et al. International Society of Urological Pathology (ISUP): consensus conference on handling and staging of radical prostatectomy specimens. Working group 5: surgical margins. Mod Pathol 2011;24:48-57 (this issue).

17 Srigley JR, Humphrey PA, Amin MB, et al. Protocol for the examination of specimens from patients with carcinoma of the prostate gland. Arch Pathol Lab Med 2009;133:1568-1576.

18 Kench J, Clouston D, Delahunt B, et al. Royal College of Pathologists of Australasia Prostate Cancer (Radical Prostatectomy) Structured Reporting Protocol. 2010, pp 54 http://www.rcpa.edu.au/Publications/StructuredReporting/CancerProtocols.htm.
19 Best S, Sawers Y, Fu VX. et al. Integrity of prostatic tissue for molecular analysis after robotic-assisted laparoscopic and open prostatectomy. Urology 2007; 70:328-332.

20 Dash A, Maine IP, Varambally S, et al. Changes in differential gene expression because of warm ischemia time of radical prostatectomy specimens. Am J Pathol 2002;161:1743-1748.

21 Chu PG, Lau SK, Weiss LM, et al. Assessment of low prostate weight as a determinant of a higher positive margin rate after laparoscopic radical prostatectomy: a prospective pathologic study of 1500 cases. Surg Endosc 2009;23:1058-1064.

22 Smith Jr JA, Chan RC, Chang SS, et al. A comparison of the incidence and location of positive surgical margins in robotic assisted laparoscopic radical prostatectomy and open retropubic radical prostatectomy. J Urol 2007;178:2385-2389.

23 Bong GW, Ritenour CW, Osunkoya AO, et al. Evaluation of modern pathological criteria for positive margins in radical prostatectomy specimens and their use for predicting biochemical recurrence. BJU Int 2009;103:327-331.

24 Murphy GP, Busch C, Abrahamsson PA, et al. Histopathology of localized prostate cancer. Consensus conference on diagnosis and prognostic parameters is localized prostate cancer, Stockholm Sweden, 12-13, 1993. Scand J Urol Nephrol Suppl 1994;162:7-42.

25 Huang CY, Beer TM, Higano CS, et al. Molecular alterations in prostate carcinomas that associate with in vivo exposure to chemotherapy: identification of a cytoprotective mechanism involving growth differentiation factor 15. Clin Cancer Res 2007;13:5825-5833.

26 True L, Coleman I, Hawley S, et al. A molecular correlate to the Gleason grading system for prostate adenocarcinoma. Proc Natl Acad Sci USA 2006; 103:10991-10996.

27 Srinivasan M, Sedmak D, Jewell S. Effect of fixatives and tissue processing on the content and integrity of nucleic acids. Am J Pathol 2002;161:1961-1971.

28 Dunn TA, Fedor H, Isaacs WB, et al. Genome-wide expression analysis of recently processed formalinfixed paraffin embedded human prostate tissues. Prostate 2009;69:214-218.

29 Lexander H, Hellman U, Palmberg C, et al. Evaluation of two sample preparation methods for prostate proteome analysis. Proteomics 2006;6:3918-3925.

30 Walton TJ, McCulloch TA, Rees RC, et al. Obtaining fresh prostate cancer tissue for research: a novel biopsy needle and sampling technique radical prostatectomy specimens. Prostate 2005;64:382-386.

31 Puchtler H, Meloan SN. On the chemistry of formaldehyde fixation and its effects on immunohistochemical reactions. Histochemistry 1985;82:201-204.

32 Start RD, Layton CM, Cross SS, et al. Reassessment of the rate of fixative diffusion. J Clin Pathol 1992; 45:1120-1121.

33 De Marzo AM, Fedor HH, Gage WR, et al. Inadequate formalin fixation decreases reliability of p27 immunohistochemical staining. Hum Pathol 2002;33:756-760.

34 Leong AS, Gilham PN. The effects of progressive formaldehyde fixation on the preservation of tissue antigens. Pathology 1989;21:266-268.

35 Varma M, Linden MD, Amin MB. Effect of formalin fixation and epitope retrieval techniques on antibody 34 beta E12 immunostaining of prostate tissues. Mod Pathol 1999;12:472-478. 
36 Diaz-Cano SJ, Brady SP. DNA extraction from formalinfixed, paraffin-embedded tissues: protein digestion as a limiting step for retrieval of high-quality DNA. Diagn Mol Pathol 1997;6:342-346.

37 Ruijter ET, Miller GJ, Aalders TW, et al. Rapid microwave-stimulated fixation of entire prostatectomy specimens. Biomed11 MPC study group. J Pathol 1997;183:369-375.

38 Jonmarker S, Valdman A, Lindberg A, et al. Tissue shrinkage after fixation with formalin injection of prostatectomy specimens. Virchows Arch 2006;449: 297-301.

39 Leong ASY, James CL, Thomas AC. Handbook of Surgical Pathology. Churchill Livingstone: New York, 1996, pp 321.

40 Emerson RE, Koch MO, Daggy JK, et al. Closest distance between tumor and resection margin in radical prostatectomy specimens: lack of prognostic significance. Am J Surg Pathol 2005;29:225-229.

41 Epstein JI, Sauvageot J. Do close but negative margins in radical prostatectomy specimens increase the risk of postoperative progression? J Urol 1997;157:241-243.

42 Chuang AY, Epstein JI. Positive surgical margins in areas of capsular incision in otherwise organ-confined disease at radical prostatectomy: histologic features and pitfalls. Am J Surg Pathol 2008;32:1201-1206.

43 Poulos CK, Koch MO, Eble JN, et al. Bladder neck invasion is an independent predictor of prostate-specific antigen recurrence. Cancer 2004;101:1563-1568.

44 Hall GS, Kramer CE, Epstein JI. Evaluation of radical prostatectomy specimens. A comparative analysis of sampling methods. Am J Surg Pathol 1992;16:315-324.

45 Cohen MB, Soloway MS, Murphy WM. Sampling of radical prostatectomy specimens. How much is adequate? Am J Clin Pathol 1994;101:250-252.

46 Sehdev AE, Pan CC, Epstein JI. Comparative analysis of sampling methods for grossing radical prostatectomy specimens for nonpalpable [stage T1C] prostatic adenocarcinoma. Hum Pathol 2001;32:494-499.

47 Montironi R, Cheng L, Mazzucchelli R, et al. Critical evaluation of the prostate from cystoprostatectomies for bladder cancer: insights from a complete sampling with the whole mount technique. Eur Urol 2008; 55:1305-1309.

48 Hollenbeck BK, Bassily N, Wei JT, et al. Whole mounted radical prostatectomy specimens do not increase detection of adverse pathological features. Urology 2000;164:1583-1586.

\section{Appendix}

The members of the ISUP Prostate Cancer Group are the following:

Adebowale Adeniran, Hikmat Al-Ahmadie, Ferran Algaba, Robert Allan, Mahul Amin, Marc Barry, Sheldon Bastacky, Dilek Baydar, Louis Bégin, Dan Berney, Athanase Billis, Liliane Boccon-Gibod, David Bostwick, Maria Brito, Tucker Burks, Christer Busch, Philippe Camparo, Liang Cheng, Cynthia Cohen, Milton Datta, Laurence de Leval, Brett Delahunt, Warick Delprado, Lars Egevad, Jonathan Epstein, Andrew Evans, Sara Falzarano, Samson Fine, Eddie Fridman, Bungo Furusato, Masoud Ganji, Lisa Glantz, Anuradha Gopalan, David Grignon, Rainer
49 Mazzucchelli R, Barbisan F, Tagliabracci A, et al Search for residual prostate cancer on pT0 radical prostatectomy after prostate biopsy. Virchows Arch 2007;450:371-378.

50 Prayer-Galetti T, Gardiman M, Sacco E, et al. Finding of no tumor (pT0) in patients undergoing radical retropubic prostatectomy for clinically localized prostate cancer. Anal Quant Cytol Histol 2007; 29:79-86.

51 Duffield AS, Epstein JI. Detection of cancer in radical prostatectomy specimens with no residual carcinoma in the issue review of slides. Am J Surg Pathol 2009;33:120-125.

52 Cao D, Hafez M, Berg K, et al. Little or no residual prostate cancer at radical prostatectomy: vanishing cancer or switched specimen? Am J Surg Pathol 2005; 29:467-473.

53 Truskinovsky AM, Sanderson H, Epstein JI. Characterization of minute adenocarcinomas of prostatectomy at radical prostatectomy. Urology 2004;64:733-737.

54 DiGiuseppe JA, Sauvageot J, Epstein JI. Increasing incidence of minimal residual cancer in radical prostatectomy specimens. Am J Surg Pathol 1997;21:174-178.

55 Zynger DL, Dimov ND, Yang XJ. Trends in carcinoma volume in 1612 radical prostatectomies: increased evidence of minimal and no residual cancer. Mod Pathol 2006;19:90A.

56 Trpkov K, Gao Y, Hay R, et al. No residual cancer on radical prostatectomy after positive 10-core biopsy: incidence, biopsy findings, and DNA specimen identity analysis. Arch Pathol Lab Med 2006;130:811-816.

57 van Oort IM, Witjes JA, Kok DE, et al. The prognostic role of the pathological T2 subclassification for prostate cancer in the 2002 Tumor-Nodes-Metastasis staging system. BJU Int 2008;102:438-441.

58 Kollerman J, Feek U, Muller H, et al. Nondetected tumor (pT0) after prolonged, neoadjuvant treatment of localized prostatic carcinoma. Eur Urol 2000;38: 714-720.

59 Descazeaud A, Zerbib M, Flam T, et al. Can pT0 stage of prostate cancer be predicted the before radical prostatectomy? Eur Urol 2006;50:1248-1252.

60 Montironi R, Cheng L, Lopez-Beltran A, et al. Stage pT0 in radical prostatectomy with no residual carcinoma and with a previous positive biopsy conveys a wrong message to clinicians and patients. Why cancer is not present in the radical prostatectomy specimen? Eur Urol 2009;56:272-274.

Grobholz, Charles Guo, Rekha Gupta, Bora Gurel, Seife Hailemariam, Ardeshir Hakam, Omar Hameed, Donna Hansel, R.-Peter Henke, Mehsati Herawi, Michelle Hirsch, Jiaoti Huang, Wei Huang, Christina Hulsbergen van de Kaa, Peter Humphrey, Kenneth Iczkowski, Edward Jones, Michael Jones, Laura Jufe, James Kench, Hyun-Jung Kim, Peter Kragel, Glen Kristiansen, Katia Ramos Moreira Leite, Claudio Daniel Lewin, Josep Lloreta, Antonio Lopez- Beltran, Scott Lucia, Dani el Luthringer, Cristina Magi-Galluzzi, Peter McCue, Teresa McHale, Jesse McKenney, Maria Merino, Rodolfo Montironi, Gabriella Nesi, George Netto, Esther Oliva, Pedro Oliveira, Adeboye Osunkoya, Gladell Paner, Anil Parwani, Maria Picken, Galina Pizov, Andrew Renshaw, Jae Ro, 
Stephen Rohan, Ruben Ronchetti, Mark Rubin, Hemamali Samaratunga, Anna Sankila, Alan Schned, Isabell Sesterhenn, Ahmed Shabaik, Rajal Shah, Jonathan Shanks, Steven Shen, Jungweon Shim, Taizo Shiraishi, VO Speights, Jr, John Srigley, Ming-Tse Sung, Sueli Suzigan, Hiroyuki Takahashi, Puay Hoon
Tan, Bernard Tetu, Satish Tickoo, John Tomaszewski, Patricia Troncoso, Kiril Trpkov, Lawrence True, Toyonori Tsuzuki, Jennifer Turner, Theo van der Kwast, Mark Weiss, Thomas Wheeler, Kirk Wojno, Keith Volmar, Chin-Lee Wu, Jorge Yao, Asli Yilmaz and Jim Zhai. 